\title{
A Systematic review of miRNAs accuracy as a diagnostic biomarker in COPD patients
}

\author{
Rexel Kuatama $^{1 * \mathbb{( D )}}$, Louis Fabio Jonathan Jusni ${ }^{1(\mathbb{D})}$, Christa Karina ${ }^{1(\mathbb{D}}$ \\ ${ }^{1}$ Medical Program, Faculty of Medicine and Health Science, Atma Jaya Catholic University of Indonesia
}

\section{A R T I C L E I N F O}

\section{Article history:}

Received 09 February 2021

Received in revised form 28 May

2021

Accepted 15 June 2021

Available online 30 June 2021

\section{Keywords:}

Acute Exacerbations of COPD, COPD,

Diagnostic,

miRNA.

*) Corresponding author:

rexelkuatama@gmail.com

\begin{abstract}
A B S T R A C T
Introduction: Chronic Obstructive Pulmonary Disease (COPD) is the third highest leading cause of early death amongst other non-communicable diseases characterized by irreversible limitations of airflow. Current reliable classification relies on forced expiratory volume in the first second (FEV1) and forced vital capacity (FVC) measured on spirometry. In order to provide more effective and individualized management, new markers are needed. Accumulating studies has shown the role of miRNA in the pathogenesis of COPD and the progression of the disease. This review aims to provide overview of the diagnostic capabilities of miRNA and identify gaps of knowledge for further studies.

Methods: A review based on Preferred Reporting Items for Systematic Reviews and Meta Analyses (PRISMA) was conducted with the database from Pubmed, Science Direct, and Proquest using the key word ("mirna" or "microrna") AND ("copd" or "chronic obstructive pulmonary disease") and diagnostic. Inclusion criteria includes studies that reported diagnostic accuracy of miRNA in patients within the last 10 years.

Results: A total of nine studies has reported diagnostic accuracies of miRNA in distinguishing COPD and normal, COPD and AECOPD, and other subtypes of COPD

Conclusion: Retrospective diagnostic analyses of miRNAs have shown several promising AUC and need to be followed up with reliable prospective designs. Further diagnostics studies, in particular those with clinical values, need to be conducted.
\end{abstract}

\section{Introduction}

Chronic Obstructive Pulmonary Disease (COPD) is the third highest leading cause of early death amongst other non-communicable diseases after ischemic heart disease and stroke. It is estimated to affect 329 million people or $5 \%$ of the global population.1 In Indonesia, COPD accounts for approximately 9.2 million of the population. ${ }^{2}$ The disease is characterized by irreversible limitations of airflow, systemic inflammation, and various possible comorbidities such as infections and lung cancer that lowers patients' quality of life.

COPD includes a wide range of spectrum in terms of progression and subtypes. Patients may differ in rates of exacerbations, response to therapy, and progression to lung cancer. Yet, current reliable classification relies solely on forced expiratory volume in the first second (FEV1) and forced vital capacity (FVC) measured on spirometry. ${ }^{3,4}$ More objective markers are needed to provide more effective and individualized management. Recent advances have elucidated the role of miRNA in the pathogenesis of COPD. MiRNAs are small non-coding RNAs ranging from 18-25 nucleotides in length that influence a variety of molecular pathways. ${ }^{4}$ Various studies have confirmed the association between several dysregulation of miRNAs and inflammatory pathways found in COPD. Furthermore, dysregulation in miRNA has been shown to be correlated with the progression of the disease. ${ }^{4-6}$ Further characterization and understanding of miRNAs in COPD might help guide clinical decisions. Hence, miRNAs hold promise as novel diagnostic, prognostic, and therapeutic approaches in COPD. This review aims to specifically provide an overview of the diagnostic capabilities of miRNA and identify gaps of knowledge for further studies.

\section{Methods}

This review uses Preferred Reporting Items for Systematic Reviews and Meta-Analyses (PRISMA) method for study selection. Literature was searched through Pubmed, 
Science Direct, and Proquest database using the key word ("mirna" or "microrna") AND ("copd" or "chronic obstructive pulmonary disease") and diagnostic and it was shown in figure 1.

Inclusion criteria used in this review are (1) studies that conduct miRNAs analysis in COPD patients, (2) Original article, (3) studies that reported diagnostic indices such as specificity, sensitivity, or Area Under the ROC Curve (AUC). Preferably, AUC was shown in the review. Test accuracy is defined based on the corresponding AUC: $<0.5$ (not useful), 0.5-0.6 (bad), 0.6-0.7 (sufficient), 0.7-0.8 (good), 0.8-0.9 (very good), and 0.9-1.0 (excellent).7 (4) studies were conducted within the last 10 years. Exclusion criteria used are (1) studies not in English, (2) abstract, reviews, case reports, or book sections. Literature obtained from database search will be first screened based on title and abstract. Potential literatures will be further assessed by reading its full text.
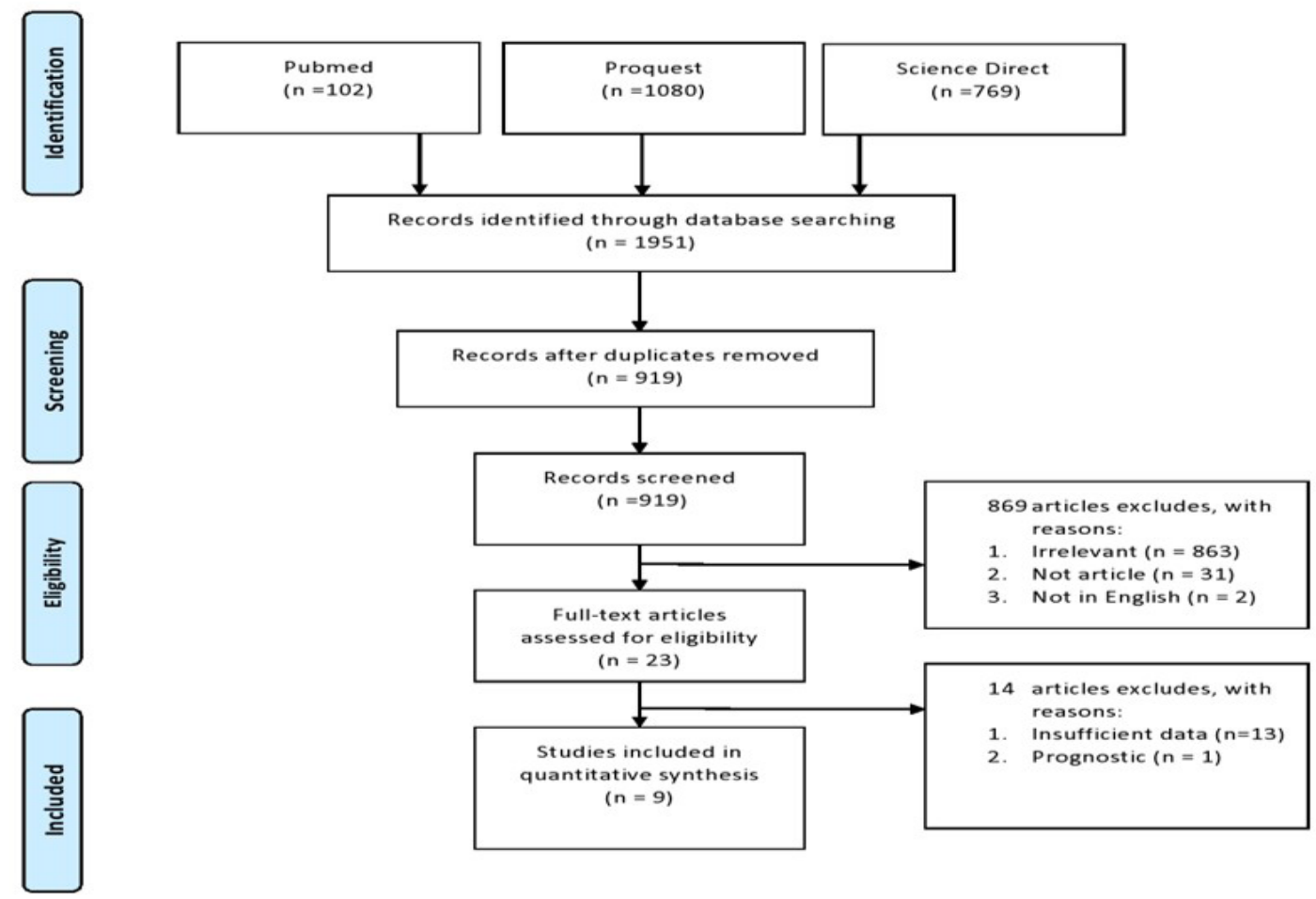

Figure 1. PRISMA flow diagram for literature search

\section{Results}

A total of 919 literatures were identified upon duplicates removal. After screening and assessment of inclusion criterias, we conclude 9 studies to be included in this review. Data such as sample size, reported miRNA, tools, purpose of classification, AUC, and type of classification were extracted and shown in table 1.

\section{COPD vs Healthy Controls}

A total of three studies reported diagnostic accuracy of miRNA in distinguishing COPD from healthy controls. Two studies utilized samples from peripheral blood serum, while one utilized exhaled breath concentrate (EBC).

Alvanegh, et al evaluate miRNA expressions in the serum of 26 COPD and 19 healthy controls. The study showed that miR-20a and miR-92a are significantly downregulated with an AUC of 0.881 and $0.943 .{ }^{8}$ Similar study was conducted by Soeda, et al with a sample of 40 COPD and 20 healthy controls. ${ }^{9}$ miRNAs was found significantly downregulated in COPD patients. Only ROC analysis of miR-106b was conducted and yielded an AUC of 0.8200 . Based on the analysis, highest sensitivity and specificity of $75 \%$ and $90 \%$ was achieved by using a cut- off level of 0.4005 .5 In a study conducted by Leidinger et al, a classification approach using 220 miRNAs yielded an accuracy of near 1 among 24 COPD and 19 healthy controls. When using only two miRNAs, hsa-miR-200a and hsamiR-518a, the accuracy yielded $0.874 .{ }^{9}$

Elfattah, et al evaluated EBC of 15 COPD and 5 healthy non-smokers as controls. The study reported significant downregulation of miR-7 in COPD patients compared to the healthy controls with an AUC of 0.909. Subanalysis revealed that patients with higher smoking index tend to have a lower level of miR-7. ${ }^{10}$

\section{COPD vs AECOPD}

Two studies reported diagnostic accuracy among Acute Exacerbation of COPD (AECOPD) and COPD. One study reported diagnostic accuracy in distinguishing frequent and infrequent AECOPD. Both studies utilize peripheral blood serum.

A study conducted by $\mathrm{Hu}$, et al confirmed that miR-125b expression could be a biomarker to distinguish COPD from AECOPD using peripheral blood serum. This study took 93 stable COPD, 87 AECOPD as samples and 100 healthy controls. It is reported that miR-125b was upregulated in AECOPD patients than stable COPD patients and healthy 
control with an AUC of $0.926 .^{11}$

Liu, et al evaluated miRNAs diagnostic accuracy in distinguishing frequent exacerbators compared from non-frequent exacerbators. The study defines frequent exacerbation as two or more incidences of exacerbations in one year. Included samples must not have episodes of exacerbation up to three months prior. The study reported AUC of 0.707 and 0.665 for miR-23a and miR-145, respectively. ${ }^{12}$

\section{Other Classification}

A total of four studies reported other aims of classification. One study distinguished AECOPD from community acquired pneumonia using peripheral blood mononuclear cells (PBMC) extracted from serum. The remaining two studies utilized peripheral blood serum. One study reported miRNAs diagnostic accuracy of eosinophilic COPD patients. One study assessed miRNA accuracy in predicting fiber shift in COPD patients. While the other distinguished COPD from lung cancer patients.

Bertrams et al evaluated genetic expression among AECOPD and community acquired pneumonia patients. The study assessed both mRNA and miRNA in peripheral blood mononuclear cells extracted from patients' blood serum. Classification approach using 120 genes (including mRNA and miRNA) was able to distinguish the two groups with an
AUC of $0.861 .^{13}$

A study by Asensio et al reported different expression profiles of eosinophilic COPD from smoking asthmatic, nonsmoking asthmatic and non-eosinophilic COPD patients. A preliminary analysis of 40 peripheral blood serum samples reported consistent significant difference of miR-619-5p and miR-4486 expression in eosinophilic COPD patients compared to others. The diagnostic accuracy of both miRNAs were further tested in a sample of 274 patients. MiR-4486 and miR-619-5p showed AUC of 0.611 and 0.632, respectively. ${ }^{14}$

Another study conducted by Donaldson, et al compare diagnostic accuracy of peripheral miRNA compared to physiological measurements in order to predict fiber shift in late stages of COPD. By using quadriceps muscle biopsy as gold standard, a score combination of physiological measurements (TLCO, 6MWD) and plasma level of miR1, miR-499, miR181 and miR-206 was able to predict fiber shift in patients with late stages of COPD with an AUC of $0.89 .{ }^{15}$

Leidinger et al conducted a study to investigate miRNA expression among lung cancer and COPD patients using peripheral blood serum. An AUC value of 0.876 was achieved using hsa-miR-675. Furthermore, by using a classification approach of 250 miRNAs, the study yielded an accuracy of 90,4\%. A simpler classification approach using 6 miRNAs was able to achieve $86.25 \%$ accuracy. ${ }^{9}$

Table 1. Characteristic of Studies

\begin{tabular}{|c|c|c|c|c|c|c|c|}
\hline Author & Sample Size & $\begin{array}{l}\text { Sample } \\
\text { Sources }\end{array}$ & Tools & & miRNA & AUC & $\begin{array}{c}\text { Types of } \\
\text { dysregulation }\end{array}$ \\
\hline \multirow[t]{2}{*}{$\begin{array}{l}\text { Alvanegh, } \\
\text { et al (2018) }\end{array}$} & \multirow[t]{2}{*}{$\begin{array}{l}\text { COPD : } 26 \\
\text { Control : } 19\end{array}$} & \multirow[t]{2}{*}{$\begin{array}{l}\text { Peripheral } \\
\text { blood }\end{array}$} & \multirow[t]{2}{*}{ qRT-PCR } & \multirow[t]{2}{*}{$\begin{array}{l}\text { COPD vs } \\
\text { control }\end{array}$} & $\operatorname{miR}-20 \mathrm{a}$ & 0,881 & $\begin{array}{l}\text { Downregulat- } \\
\text { ed in COPD }\end{array}$ \\
\hline & & & & & miR-92a & 0,902 & $\begin{array}{l}\text { Downregulat- } \\
\text { ed in COPD }\end{array}$ \\
\hline $\begin{array}{l}\text { Soeda, et al } \\
(2012)\end{array}$ & COPD : 40 Control : 20 & $\begin{array}{c}\text { Peripheral } \\
\text { blood }\end{array}$ & RT-PCR & $\begin{array}{l}\text { COPD vs } \\
\text { control }\end{array}$ & miR-106b & 0,82 & $\begin{array}{c}\text { Downregulat- } \\
\text { ed in COPD }\end{array}$ \\
\hline \multirow[t]{4}{*}{$\begin{array}{l}\text { Leidinger, } \\
\text { et al (2010) }\end{array}$} & \multirow[t]{4}{*}{$\begin{array}{l}\text { Lung cancer: } 28 \\
\text { Control : } 19\end{array}$} & \multirow[t]{4}{*}{$\begin{array}{l}\text { Peripheral } \\
\text { blood }\end{array}$} & \multirow[t]{4}{*}{ qRT-PCR } & \multirow[t]{2}{*}{$\begin{array}{l}\text { COPD vs } \\
\text { control }\end{array}$} & $\begin{array}{l}\text { A classification } \\
\text { approach of } 220 \\
\text { miRNAs }\end{array}$ & $\begin{array}{l}\text { Accuracy } \\
: 1\end{array}$ & - \\
\hline & & & & & $\begin{array}{c}\text { hsa-miR-200a } \\
\text { and hsamiR- } \\
518 \mathrm{a}\end{array}$ & $\begin{array}{l}\text { Accuracy } \\
: 0.837\end{array}$ & $?$ \\
\hline & & & & \multirow[t]{2}{*}{$\begin{array}{l}\text { COPD } \\
\text { vs lung } \\
\text { cancer }\end{array}$} & $\begin{array}{c}\text { A classification } \\
\text { approach of } 220 \\
\text { miRNAs }\end{array}$ & $\begin{array}{l}\text { Accuracy } \\
: 0,904\end{array}$ & - \\
\hline & & & & & hsa-miR-662 & 0,884 & $\begin{array}{l}\text { Downregulat- } \\
\text { ed in COPD }\end{array}$ \\
\hline $\begin{array}{l}\text { Elfattah, et } \\
\text { al (2017) }\end{array}$ & $\begin{array}{l}\text { COPD : } 15 \\
\text { Control: } 5\end{array}$ & $\mathrm{EBC}$ & $\begin{array}{l}\text { spectro- } \\
\text { photom- } \\
\text { eter }\end{array}$ & $\begin{array}{l}\text { COPD vs } \\
\text { control }\end{array}$ & miRNA7 & 0,909 & $\begin{array}{l}\text { Downregulat- } \\
\text { ed in COPD }\end{array}$ \\
\hline $\begin{array}{l}\text { Hu, et al } \\
(2017)\end{array}$ & $\begin{array}{c}\text { Frequent: } 87 \text { patients } \\
\text { Infrequent: } \\
93 \text { patients }\end{array}$ & $\begin{array}{l}\text { Peripheral } \\
\text { blood }\end{array}$ & qRT-PCR & $\begin{array}{l}\text { AECOPD } \\
\text { vs COPD }\end{array}$ & $\operatorname{miR}-125 b$ & 0,926 & $\begin{array}{l}\text { Upregulated in } \\
\text { AECOPD }\end{array}$ \\
\hline \multirow[t]{2}{*}{$\begin{array}{l}\text { Liu, et al } \\
\text { (2018) }\end{array}$} & $\begin{array}{l}\text { Frequent : } 32 \text { patients } \\
\text { Infrequent : } 18 \text { patients }\end{array}$ & $\begin{array}{l}\text { Peripheral } \\
\text { blood }\end{array}$ & qRT-PCR & $\begin{array}{l}\text { Frequent } \\
\text { vs infre- } \\
\text { quent esc- } \\
\text { erbations }\end{array}$ & $\operatorname{miR}-23 a$ & 0,707 & $\begin{array}{l}\text { Downregulat- } \\
\text { ed in AE- } \\
\text { COPD }\end{array}$ \\
\hline & & & & & miR-145 & 0,665 & \\
\hline
\end{tabular}




\begin{tabular}{|c|c|c|c|c|c|c|c|}
\hline $\begin{array}{l}\text { Bertrams, } \\
\text { et al } \\
(2010)\end{array}$ & $\begin{array}{c}\text { CAP: } 13 \\
\text { AECOPD : } 13\end{array}$ & $\begin{array}{l}\text { Peripheral } \\
\text { blood }\end{array}$ & $\begin{array}{l}\text { Microar- } \\
\text { ray/ } \\
\text { TLDA }\end{array}$ & $\begin{array}{l}\text { AECOPD } \\
\text { vs CAP* }\end{array}$ & $\begin{array}{c}\text { A classifi } \\
\text { approach of } \\
\text { mRNA/miRA } \\
\text { (120 genes })\end{array}$ & 0,861 & - \\
\hline \multirow{2}{*}{$\begin{array}{l}\text { Asen- } \\
\text { sio, et al } \\
(2019)\end{array}$} & $\begin{array}{l}\text { Non-smoker Asthma: } \\
85\end{array}$ & \multirow[t]{2}{*}{$\begin{array}{l}\text { Peripheral } \\
\text { blood }\end{array}$} & \multirow[t]{2}{*}{ qRT-PCR } & \multirow{2}{*}{$\begin{array}{l}\text { es- } \\
\text { COPD** } \\
\text { vs others }\end{array}$} & miR-619-5p & 0,632 & $\begin{array}{l}\text { Downregulat- } \\
\text { ed in eCOPD }\end{array}$ \\
\hline & $\begin{array}{c}\text { Smoker Asthma :44 } \\
\text { COPD: } 84 \\
\text { COPDe }: 71\end{array}$ & & & & $\operatorname{miR}-4486$ & 0,616 & $\begin{array}{l}\text { Downregulat- } \\
\text { ed in eCOPD }\end{array}$ \\
\hline $\begin{array}{l}\text { Donald- } \\
\text { son et al } \\
(2013)\end{array}$ & $\begin{array}{l}\text { GOLD III : } 38 \\
\text { GOLD IV : } 31\end{array}$ & $\begin{array}{l}\text { Peripheral } \\
\text { blood }\end{array}$ & qRT-PCR & $\begin{array}{l}\text { Predict fi- } \\
\text { bre I shift } \\
\text { in GOLD } \\
\text { III and IV } \\
\text { patient }\end{array}$ & $\begin{array}{l}\text { a score com- } \\
\text { bination of } \\
\text { physiological } \\
\text { measure- } \\
\text { ments (TLCO, } \\
\text { 6MWD) and } \\
\text { plasma level of } \\
\text { miR-1, miR- } \\
499, \text { miR-181 } \\
\text { and miR-206 }\end{array}$ & 0.89 & - \\
\hline
\end{tabular}

Only relevant data related to diagnostic accuracy is shown on the table.

*community acquired pneumonia

**eosinophilic COPD

\section{Discussion}

To the best of our knowledge, this is the first review to discuss diagnostic capabilities of miRNAs in COPD. As the previous review has summarized findings of dysregulated miRNAs in COPD patients. This review aims to summarize studies which have reported diagnostic accuracies. No studies reported prospective design.

Samples from peripheral blood serum and exhaled breath concentrate were able to show miRNAs with very good to excellent AUC ranging from 0.881-0.909. Interestingly, these studies reported decent AUC regardless of whether the controls are non-smokers, ex-smokers or smokers. Previous literature has shown that smoking, particularly pack years, influences miRNA expression. ${ }^{4,16}$ Despite showing decent AUC, distinguishing normal patients from COPD using miRNA is irrelevant as it is easily achieved by spirometry and clinical diagnosis. Regardless of the lack of clinical utility, the diagnostic accuracies shown strengthens the notion that expression of miRNAs are significantly different in COPD patients.

On the other hand, characterizing AECOPD is of great clinical interest. AECOPD is a clinical diagnosis characterized by increased severity of symptoms. It is associated with increased risk of mortality (respiratory failure) and morbidity (cardiac dysfunction, quality of life, etc). Like COPD, this condition varies in etiologies, rate of progression, and response to therapy. ${ }^{17}$ Hence, biomarkers might serve as a key role in AECOPD management. In a study by $\mathrm{Hu}$, et al. miR-125b was found to be an excellent biomarker in distinguishing AECOPD from stable COPD with excellent AUC of 0.926. ${ }^{11}$ However, it is worth noticing that these studies distinguished 'predetermined' samples. In clinical settings, biomarkers for distinguishing AECOPD and COPD are irrelevant as AECOPD is a clinical diagnosis. In future studies, a prospective design to elucidate which miRNA profiles predict progression to AECOPD is of better clinical value.
Several AECOPD studies offered promising clinical diagnostic value. In a study by Liu, et al, diagnostic accuracies to distinguish frequent and infrequent exacerbations were conducted. Being able to distinguish frequent and infrequent exacerbators will inform physicians about patients' prognosis and guide therapeutic approaches. However, miR-23a and miR-145 only showed poor to sufficient levels of AUC (0.665-0.707). ${ }^{12}$ Another clinically useful classification is to distinguish AECOPD from community acquired pneumonia as both often show overlapping clinical presentation. ${ }^{18}$ In one study, a classification approach consisting of 120 mRNA and miRNA showed a very good AUC of $0.861 .{ }^{13}$ However, further studies are needed to confirm such complex classification in another cohort. Furthermore, the study utilizes specific PBMC samples analysis that needs to be reproduced in other studies.

One study was able to distinguish eosinophilic COPD, a subtype of COPD marked by significant elevation of eosinophils, from asthmatic patients and non-eosinophilic COPD. As they often share similar presentations, eosinophilic COPD and smoking asthma (asthmatic patients with a history of smoking) were often grouped together as Asthma-COPD Overlap (ACO). Yet, eosinophilic COPD has been shown to have different clinical characteristics with greater response to corticosteroid therapy. ${ }^{14,19}$ Thus, distinguishing both would serve a clinical value. However, the reported miR-4486 and miR-619-5p AUC was only sufficient. Nonetheless, the study did find different significant miRNA dysregulation indicating possible different mechanisms between the two groups. ${ }^{14}$

One study aimed to predict fiber shift in COPD patients using peripheral miRNAs previously found associated with skeletal dysfunction. Overtime, COPD patients, especially those in later stages, experience reduction in muscle mass and alteration in fiber composition that increase difficulty of breathing. Predicting this alteration 
might serve as a prognostic measure or even therapeutic guidance if future drugs were to slow its rate. Donaldson et al was able to use miRNA combined with other muscle physiological measures to predict reduction of type I fiber in stage 3 and 4 COPD patients with an almost excellent AUC of 0.89. Interestingly, when miRNAs were used in combination, the AUC increases compared to when using muscle physiological measurements alone. ${ }^{15}$ This shows that miRNA might be combined with other clinical measurements to provide better accuracy.

COPD patients can have up to five times risk in developing lung cancer. These patients have limited options as several therapies such as surgical resection are often contraindicated. ${ }^{20}$ Leidinger et al was able to distinguish lung cancer patients from COPD with an accuracy of 0.8625 and 0.904 by using a classified set of 220 and 6 miRNAs. By using only a hsa-miR-675 as a single measure, 0.876 AUC (very good) was still achieved. ${ }^{9}$ As explained before, the study is retrospective in nature and therefore does not elucidate the risk of cancer progression in COPD patients. A prospective study has been conducted by Keller, et al which follows up 534 COPD patients for 54 months. Downregulation of nine statistically significant miRNAs (hsa-miR-4695-3p, hsa-miR-517a-3p, hsa-miR-4785, hsa-miR-548d-5p, hsa-miR-7109-3p, hsa-miR-548ay5p, hsa-miR-320e, hsa-miR-320c and hsa-miR-519d$3 p)$ was observed when comparing those who do and do not develop cancer. ${ }^{21}$ However, the study did not conduct diagnostic accuracy analysis.

\section{Conclusion}

Upon our literature search, we observed a number of studies, including those discussed in this review, that reported only significance testing of miRNAs level among case groups and control without diagnostic accuracy. As this review only includes those with such indices, it may not reflect the whole miRNAs that is promising to be a biomarker. Further diagnostics studies, in particular those with clinical values, need to be conducted. One example would be to predict response to therapy. Most studies evaluate miRNAs as a single measure. Another possible approach would be to combine miRNAs with other clinical measurements to create criteria with higher diagnostic accuracy, as shown in a study by Donaldson, et al.

All in all, retrospective diagnostic analyses of miRNAs have shown several promising AUC and need to be followed up with reliable prospective designs. When conducting diagnostic analysis, we recommend researchers to apply ROC curve analysis and AUC statistics rather than a single diagnostic measure such as sensitivity and specificity that is subjectively reliant on the level of cutoffs determined. As AUC considers all sensitivity and specificity in all possible cutoffs, it allows objective comparison of miRNAs diagnostic capabilities among studies. The findings of these studies need to be further assessed in an external cohort in order to yield a reliable diagnostic biomarker for COPD.

\section{Acknowledgement}

There was no funding for this review paper.

\section{Conflict of Interest}

The author stated there is no conflict of interest

\section{References}

1. Ahmed R, Robinson R, Mortimer $\mathrm{K}$. The epidemiology of noncommunicable respiratory disease in sub-Saharan Africa, the Middle East, and North Africa. Malawi Med J 2017; 29: 203-211.

2. PERHIMPUNAN DOKTER PARU INDONESIA. Pers Release Perhimpunan Dokter Paru Indonesia dalam rangka WORLD COPD DAY 2018, https://www.klikpdpi.com/index. php? mod $=$ article \&sel $=8720$ (2020).

3. Riley CM, Sciurba FC. Diagnosis and Outpatient Management of Chronic Obstructive Pulmonary Disease: A Review. JAMA 2019; 321: 786-797.

4. Salimian J, Mirzaei H, Moridikia A, et al. Chronic obstructive pulmonary disease: MicroRNAs and exosomes as new diagnostic and therapeutic biomarkers. J Res Med Sci 2018; 23: 27.

5. Soeda S, Ohyashiki JH, Ohtsuki K, et al. Clinical relevance of plasma miR-106b levels in patients with chronic obstructive pulmonary disease. Int J Mol Med 2013; 31: 533-539.

6. Kara M, Kirkil G, Kalemci S. Differential Expression of MicroRNAs in Chronic Obstructive Pulmonary Disease. Adv Clin Exp Med Off organ Wroclaw Med Univ 2016; 25: 21-26.

7. Hosmer DW, Lemeshow S. Applied Logistic Regression. New York: A Wiley-Interscience Publication, 2013.

8. Alvanegh AG, Tavallaei M, Edalat H. Severe decline in mir-20a and mir-92a in the context of the mir-17-92 cluster: Ideal biomarkers of various COPD subtypes. Acta Med Iran 2019; 57: 17-26.

9. Leidinger P, Keller A, Borries A, et al. Specific peripheral miRNA profiles for distinguishing lung cancer from COPD. Lung Cancer 2011; 74: 41-47.

10. Abd Elfattah N, Ali-Labib R. MicroRNA7 expression in exhaled breath condensate of smokers with chronic obstructive pulmonary disease: A potential biomarker? Egypt J Chest Dis Tuberc 2017; 66: 577-580.

11. Hu H-L, Nie Z-Q, Lu Y, et al. Circulating miR-125b but not miR125 a correlates with acute exacerbations of chronic obstructive pulmonary disease and the expressions of inflammatory cytokines. Medicine (Baltimore) 2017; 96: e9059.

12. Liu X, Qu J, Xue W, et al. Bioinformatics-based identification of potential microRNA biomarkers in frequent and non-frequent exacerbators of COPD. Int J COPD 2018; 13: 1217-1228.

13. Bertrams W, Griss K, Han M, et al. Transcriptional analysis identifies potential biomarkers and molecular regulators in pneumonia and COPD exacerbation. Sci Rep 2020; 10: 1-9.

14. Asensio VJ, Tomás A, Iglesias A, et al. Eosinophilic COPD Patients Display a Distinctive Serum miRNA Profile From Asthma and Noneosinophilic COPD. Arch Bronconeumol 2020; 56: 234-241.

15. Donaldson A, Natanek SA, Lewis A, et al. Increased skeletal musclespecific microRNA in the blood of patients with COPD. Thorax 2013; 68: 1140-1149.

16. Fujii T, Shimada K, Nakai T, et al. MicroRNAs in Smoking-Related Carcinogenesis: Biomarkers, Functions, and Therapy. J Clin Med 2018; 7: 98.

17. MacIntyre N, Yuh $\mathrm{CH}$. Acute exacerbations and respiratory failure in chronic obstructive pulmonary disease. Proc Am Thorac Soc 2008; 5: $530-535$.

18. Husebø GR, Grønseth R, Lehmann S, et al. Pneumonia vs nonpneumonia in COPD exacerbations - different risks? Eur Respir J 2018; 52: PA2277.

19. Kolsum U, Ravi A, Hitchen P, et al. Clinical characteristics of eosinophilic COPD versus COPD patients with a history of asthma. Respir Res 2017; 18: 73.

20. López-Baltanás R, Encarnación Rodríguez-Ortiz M, Canalejo A, et al. Magnesium supplementation reduces inflammation in rats with induced chronic kidney disease. Eur J Clin Invest 2021; e13561.

21. Keller A, Fehlmann T, Ludwig N, et al. Genome-wide MicroRNA Expression Profiles in COPD: Early Predictors for Cancer Development. Genomics Proteomics Bioinformatics 2018; 16: 162171. 